\title{
Flow-mediated vasodilation is not impaired when HDL-cholesterol is lowered by substituting carbohydrates for monounsaturated fat
}

\author{
Nicole M. de Roos ${ }^{1 *}$, Michiel L. Bots ${ }^{2}$, Els Siebelink ${ }^{1}$, Evert Schouten ${ }^{1}$ and Martijn B. Katan ${ }^{1,3}$ \\ ${ }^{1}$ Division of Human Nutrition and Epidemiology, Wageningen University, Wageningen, the Netherlands \\ ${ }^{2}$ Julius Center for Patient Oriented Research, University Medical Center, Utrecht, the Netherlands \\ ${ }^{3}$ The Wageningen Center for Food Sciences, Wageningen, the Netherlands \\ (Received 29 September 2000 - Revised 8 January 2001 - Accepted 30 January 2001)
}

\begin{abstract}
Low-fat diets, in which carbohydrates replace some of the fat, decrease serum cholesterol. This decrease is due to decreases in LDL-cholesterol but in part to possibly harmful decreases in HDL-cholesterol. High-oil diets, in which oils rich in monounsaturated fat replace some of the saturated fat, decrease serum cholesterol mainly through LDL-cholesterol. We used these two diets to investigate whether a change in HDL-cholesterol would change flow-mediated vasodilation, a marker of endothelial function. We fed thirty-two healthy volunteers two controlled diets in a $2 \times 3.5$ weeks' randomised cross-over design to eliminate variation in changes due to differences between subjects. The low-fat diet contained $59.7 \%$ energy (en\%) as carbohydrates and $25.7 \mathrm{en} \%$ as fat $(7.8 \mathrm{en} \%$ as monounsaturates); the oil-rich diet contained $37.8 \mathrm{en} \%$ as carbohydrates and $44.4 \mathrm{en} \%$ as fat (19.3 en $\%$ as monounsaturates). Average (SD) serum HDL-cholesterol after the low-fat diet was 0.21 (SD 0.12) $\mathrm{mmol} / \mathrm{l}(8.1 \mathrm{mg} / \mathrm{dl})$ lower than after the oil-rich diet. Serum triacylglycerols were 0.22 (SD 0.28$) \mathrm{mmol} / \mathrm{l}(19.5 \mathrm{mg} / \mathrm{dl}$ ) higher after the low-fat diet than after the oil-rich diet. Serum LDL and homocysteine concentrations remained stable. Flow-mediated vasodilation was 4.8 (SD 2.9) after the low-fat diet and 4.1 (SD 2.7) after the oil-rich diet (difference $0.7 \%$; $95 \%$ CI $-0.6,1.9$ ). Thus, although the low-fat diet produced a lower HDL-cholesterol than the high-oil diet, flow-mediated vasodilation, an early marker of cardiovascular disease, was not impaired.
\end{abstract}

Lipoproteins: Cardiovascular disease: Diet

Diets low in saturated fats and high in carbohydrates are often advocated to reduce the risk of cardiovascular disease (CVD) because they lower serum total and LDL-cholesterol (Schaefer et al. 1995; Clarke et al. 1997; Turley et al. 1998). However, there has been a debate about whether to lower the intake of saturated fats by decreasing total fat intake or by replacing them with cis-unsaturated fats. Supporters of low-fat diets argue that replacement of fat by carbohydrates will not only decrease risk of CVD through lowering of serum cholesterol but will also help people lose weight (Connor \& Connor, 1997) and thus prevent obesity (Bray \& Popkin, 1998; Miller et al. 1998). However, others argue that low-fat diets might not be the wisest recommendation because these diets lower HDL-cholesterol (Katan et al. 1997), which may increase the risk of CHD (Pearson et al. 1979; Gordon et al. 1986, 1989; Huttunen et al. 1991; Castelli et al. 1992; Kitamura et al. 1994; de Backer et al. 1998; Ballantyne et al. 1999; Sharrett et al.
1999; Sorlie et al. 1999). HDL-cholesterol is not lowered when saturated and trans fatty acids are replaced by unsaturated vegetable oils, and therefore diets rich in vegetable oils might be a good alternative to low-fat diets (Katan et al. 1997).

To investigate whether the difference in HDL-cholesterol after a low-fat diet and a high-oil diet would affect risk of CVD, we used flow-mediated vasodilation (FMD) of the brachial artery as an outcome variable. FMD is a measure of endothelial function, which is believed to be an early stage of CVD (Kuhn et al. 1991; Clarkson et al. 1997). FMD of the brachial artery is mediated by nitric oxide released by the endothelial cells (Joannides et al. 1995) and can be measured non-invasively. We chose FMD because it appears to be predictive of cardiovascular events (Neunteufl et al. 1999).

In a previous study (de Roos et al. 2001) we showed that intake of trans fatty acids reduced serum HDL-cholesterol

\footnotetext{
Abbreviations: CVD, cardiovascular disease; en \%, percentage of energy; FMD, flow-mediated vasodilation.

* Corresponding author: Ms N. M. de Roos, fax + 31317483342 , email nicole.deroos@staff.nutepi.wau.nl
} 
and impaired FMD in healthy men and women. Although the results of that study seemed to be compatible with a causal relationship between HDL-cholesterol and FMD, a verification of the results was needed. Thus, we investigated whether the difference in HDL-cholesterol after a low-fat diet and an oil-rich diet affected FMD. We applied Bayesian methods to integrate the existing evidence for a protective effect of HDL-cholesterol with the present data.

\section{Methods}

The study was approved by the Medical Ethics Committee of Wageningen University. Each volunteer signed an informed consent form.

\section{Subjects}

We recruited thirty-nine non-smoking men and women by advertising in the university newspaper and by personally inviting subjects who had taken part in previous studies. We selected subjects on the basis of a medical questionnaire, serum cholesterol $(<8 \mathrm{mmol} / \mathrm{l})$ and triacylglycerols $(<2 \mathrm{mmol} / \mathrm{l})$, urinary protein $(<0.3 \mathrm{~g} / \mathrm{l})$ and glucose $(<5.5 \mathrm{mmol} / \mathrm{l})$, and a good-quality ultrasound image of the brachial artery. We enrolled thirty-five subjects. One subject withdrew from the study after 1 week because he could not comply with the study protocol. The study was completed by thirty-four subjects; thirteen men and twentyone women with mean age 27 (range 19-59) years. Their mean (SD) baseline body weight was 68 (SD 9) $\mathrm{kg}$, BMI 22 (SD $2 \cdot 3) \mathrm{kg} / \mathrm{m}^{2}$, fasting total cholesterol 4.6 (SD 0.8) $\mathrm{mmol} / \mathrm{l}$ and triacylglycerols $1 \cdot 2(\mathrm{SD} 0 \cdot 5) \mathrm{mmol} / \mathrm{l}$.

\section{Study design}

Our aim was to test whether a difference in HDLcholesterol induced by two different diets would result in a difference in FMD. To minimise the variation in the differences we chose a cross-over design. The order in which the two diets were given was randomly allocated.

We provided two controlled diets for 3.5 weeks each without a wash-out period. The diets were given in a $28 \mathrm{~d}$ menu cycle. On Mondays to Fridays subjects came to our dining room and ate a hot meal under our supervision. All other foods (bread; margarine; meat and/or cheese; honey, jam, or sprinkles; fruit; milk and/or yogurt) were provided in a package for consumption at home, as was food for the weekends.

On $2 \mathrm{~d}$ during the last week of each diet period, after subjects had consumed the diets for at least $22 \mathrm{~d}$, we measured FMD and serum lipids in the subjects. The measurements were performed 1-2 d apart. Because not all subjects could be measured on the same day, they received the diets for 24-27 d (mean $25 \mathrm{~d}$ ).

\section{Diets}

The two diets consisted of conventional food items. The composition of the two diets was calculated to change the concentration of HDL-cholesterol without changing LDLcholesterol. Therefore, it was impossible to match the two diets for saturated and polyunsaturated fatty acid intake. We used a low-fat margarine, low-fat dairy products, and extra carbohydrate in the low-fat diet, and olive oil, margarine, and full-fat dairy products in the oil-rich diet (Table 1). The composition of the experimental diets was calculated using food composition tables (Anonymous, 1996; Hulshof et al. 1999). We checked the composition of the diets by collecting duplicates of all meals. The analysed values were similar to the calculated composition.

Habitual energy intake of the subjects was estimated from a food frequency questionnaire. We designed menus for fourteen levels of energy intake, ranging from 7 to $20 \mathrm{MJ} / \mathrm{d}$. The subjects were allocated to an energy intake

Table 1. Food items $(\mathrm{g} / \mathrm{d})$ provided in a $11 \mathrm{MJ}$ menu of the low-fat and unsaturated oil-rich diet

\begin{tabular}{|c|c|c|c|}
\hline & Food item & Low-fat diet & Oil-rich diet \\
\hline \multirow[t]{6}{*}{ Food items that differed in amount and composition } & Bread $^{*}$ & $233 \cdot 0$ & $200 \cdot 0$ \\
\hline & Cookies* & $30 \cdot 0$ & $45 \cdot 0$ \\
\hline & Sauce and gravy* & $70 \cdot 0$ & $70 \cdot 0$ \\
\hline & Salad dressing $†$ & $15 \cdot 0$ & $15 \cdot 0$ \\
\hline & Dessertł & $250 \cdot 0$ & $125 \cdot 0$ \\
\hline & Table spread§ & $26 \cdot 0$ & $35 \cdot 0$ \\
\hline \multirow[t]{11}{*}{ Foods that differed in amount only } & Starch (potatoes, rice, pasta, bulgur) & $270 \cdot 0$ & $180 \cdot 0$ \\
\hline & Vegetables & $230 \cdot 0$ & $150 \cdot 0$ \\
\hline & Fruit & $248 \cdot 0$ & $124 \cdot 0$ \\
\hline & Salad & 38.0 & 38.0 \\
\hline & Meat & $82 \cdot 0$ & $68 \cdot 0$ \\
\hline & Milk, $1.5 \%$ fat & $250 \cdot 0$ & $200 \cdot 0$ \\
\hline & Eggs & 17.5 & $28 \cdot 0$ \\
\hline & Cheese, $31 \%$ fat & $16 \cdot 0$ & $32 \cdot 0$ \\
\hline & Meat (filling) & $36 \cdot 0$ & $36 \cdot 0$ \\
\hline & Sweet fillings (honey, jam, sprinkles, etc.) & $39 \cdot 0$ & $26 \cdot 0$ \\
\hline & Crisps & $9 \cdot 0$ & $9 \cdot 0$ \\
\hline
\end{tabular}

\footnotetext{
* Made with margarine (Blueband, Unilever, Vlaardingen, the Netherlands) and extra carbohydrates (Fantomalt, N.V. Nutricia, Zoetermeer Holland) in the low-fat die and with olive oil (Carbonell, Cordoba, Spain) in the oil-rich diet.

† Made with low-fat salad dressing (5 g fat/100 g) and extra carbohydrates (Fantomalt, N.V. Nutricia, Zoetermeer Holland) in the low-fat diet and with olive oil in the oil-rich diet.

‡ Low-fat desserts in the low-fat diet and full-fat desserts in the oil-rich diet.

$\S$ Low-fat margarine (35 g fat/100 g) in the low-fat diet and full-fat margarine $(80 \mathrm{~g} \mathrm{fat} / 100 \mathrm{~g})$ in the oil-rich diet.
} 
level close to their habitual energy intake. We provided $90 \%$ of energy (en\%) and all food was weighed out for each subject. The remaining $10 \mathrm{en} \%$ had to be chosen from a list of low-fat food items. Subjects recorded their choice from this low-fat food list in a diary.

We measured body weight twice a week; if body weight changed more than $1 \mathrm{~kg}$ subjects were switched to a different energy intake level.

\section{Blood lipids}

We took fasting blood samples on two separate days after day 22 of each diet. All four blood samples of each subject were analysed in duplicate within one run. Total cholesterol and triacylglycerols (Cholesterol Flex ${ }^{\mathrm{TM}}$ and Triglycerides Flex $^{\mathrm{TM}}$ reagent cartridge, Dade Behring, Newark, NJ, USA) and HDL-cholesterol (liquid N-geneous ${ }^{\mathrm{TM}}$ HDL-C assay, Instruchemie BV, Hilversum, the Netherlands) were measured, and LDL-cholesterol was calculated using the Friedewald formula. The coefficient of variation of sixtyfour duplicate measurements was $0.4 \%$ for total cholesterol, $1.5 \%$ for triacylglycerols, and $1.1 \%$ for HDL-cholesterol.

\section{Brachial artery measurements}

All brachial artery measurements were done in subjects after an overnight fast. We assessed endothelial function as FMD of the brachial artery as described elsewhere (Sorensen et al. 1995; Celermajer et al. 1996). We measured the diameter of the artery at rest and at maximum vasodilation, and calculated the FMD as the percentage increase. All measurements were done at end-diastole by the use of the R-wave of the electrocardiogram.

The ultrasound images were made with a $7.5 \mathrm{MHz}$ linear array transducer of an Ultramark ${ }^{\mathrm{TM}} 9$ HDI duplex scanner. All images were stored on super-VHS videotapes for offline analysis.

All measurements were done by one technician in a temperature-controlled room (range 20-24 ${ }^{\circ}$ ). Subjects were lying down with the right arm in two arm support cushions. An inflatable cuff was placed around the forearm. The measurements were done at the site of the antecubital crease. The position of the transducer was held constant during the measurements with a specially developed transducer arm fixature (TAF® method developed by Meijer and colleagues, Vascular Imaging Center, The Julius Center for Patient Oriented Research, UMC Utrecht, the Netherlands).

We first obtained an optimal two-dimensional B-mode ultrasound image of the brachial artery at rest. The search was for a good trailing edge of the adventitia interface of the near wall and a leading edge of the media-adventitia interface of the far wall of the artery. Three optimal images were frozen at the R-wave of the electrocardiogram, at enddiastole, and stored on videotape. These images were used to calculate the resting diameter of the artery. We then inflated the cuff to $250 \mathrm{mmHg}$ and kept this pressure constant for $5 \mathrm{~min}$ to induce ischaemia in the forearm and hand. After 5 min the cuff was deflated. The image of the brachial artery was again optimised and changes in the diameter of the artery were recorded during the next $5 \mathrm{~min}$. Every $15 \mathrm{~s}$ a frozen image was stored on videotape. At the end of the second feeding period we also measured endothelium-independent vasodilatation after a sublingual dose of $400 \mu \mathrm{g}$ of nitroglycerin.

All images were read at the Vascular Imaging Center of the University Medical Center in Utrecht by one reader who was blinded to the treatment. The reader rated the quality of the images as class 1 (perfect), class 2 (fair), class 3 (marginal) to class 4 (unfit for use). All thirty-four subjects were measured twice on both diets, so we had four measurements per subject. Of these 136 measurements, sixteen were rated as marginal and three as unfit. We only used measurements rated perfect or fair, which left us with thirty-two subjects for whom we had observations on both diets. At a mean FMD of $4.5 \%$-units, the within-subjects SD was $2.9 \%$-units so the corresponding coefficient of variation was $65 \%$. The biggest difference between duplicate FMD measurements was $9 \%$-units (measurements: -8.05 and $0.95 \%$-units); the smallest difference was 0.01 \%-units (measurements: 2.83 and $2.82 \%$-units). The coefficient of variation of the diameter of the brachial artery at rest was $6.9 \%$.

\section{Serum homocysteine}

Total homocysteine concentrations in serum were measured with HPLC and fluorimetric detection (Ubbink et al. 1991; Ueland et al. 1993). The coefficient of variation was $3.2 \%$ within and $8 \%$ between runs.

\section{Statistics}

We averaged the duplicate measurements in each dietary period and then calculated for each subject the difference between treatments. We tested whether these differences were significantly different from zero with Student's $t$ test for paired samples. We give two-sided $95 \% \mathrm{CI}$ for the differences. All statistical analyses were performed with the SAS System for Windows (SAS Institute Inc., Cary, NC, USA), release $6 \cdot 12$.

We used Bayesian statistics to combine existing evidence for a protective effect of HDL-cholesterol with the present data. The existing evidence was used to postulate an a priori probability (i.e. before the present study) for a direct effect of HDL-cholesterol on FMD. We postulated an a priori probability of $75 \%$. The effect size was estimated from data of our previous study (de Roos et al. 2001): we hypothesised that FMD would be $1 \%$-unit lower on the low-fat diet than on the high-oil diet. The rationale behind this hypothesis was that in the previous study a decrease in HDL-cholesterol of $0.36 \mathrm{mmol} / \mathrm{l}$ went together with a decrease in FMD of $1.8 \%$-units. In the present study we expected to see a decrease in HDLcholesterol of $0.20 \mathrm{mmol} / \mathrm{l}$ on the low-fat diet and therefore a decrease in FMD of $1 \%$-unit $(1 / 0 \cdot 2=1 \cdot 8 / 0 \cdot 36)$. We used the Bayes factor, which was derived from the $P$-value from the Student's $t$ test, to evaluate whether the data from the present study changed the a priori probability (Goodman, 1999). 
Table 2. Diet composition in the low-fat and in the unsaturated oilrich period

\begin{tabular}{lcc}
\hline Component & Low-fat diet & Oil-rich diet \\
\hline Energy (MJ/d) & 11.4 & 11.3 \\
(kcal/d) & 2702 & 2693 \\
Carbohydrate (energy\%) & 59.7 & 37.8 \\
Protein (energy\%) & 13.4 & 16.4 \\
Total fat (energy\%) & 25.7 & 44.4 \\
Saturated & 10.3 & 15.5 \\
Lauric acid (C12:0) & 0.8 & 1.3 \\
Myristic acid (C14:0) & 0.9 & 1.5 \\
Palmitic acid (C16:0) & $5 \cdot 7$ & 7.9 \\
Stearic acid (C18:0) & 2.2 & 3.7 \\
Monounsaturated, total & 7.8 & 19.3 \\
Polyunsaturated & 6.9 & 8.8 \\
Cholesterol (mg/MJ) & 25.9 & 34.1 \\
(mg/d) & 294 & 386 \\
Fibre (g/MJ) & 2.6 & 2.4 \\
(g/d) & 29.5 & 27.1 \\
Alcohol (energy\%) & 1.3 & 1.2 \\
\hline
\end{tabular}

In both periods $90 \%$ of energy was provided and duplicate meals were analysed. The remaining $10 \%$ of energy was chosen from a list of low-fat food items and the composition of these was calculated.

\section{Results}

All results refer to eleven men and twenty-one women for whom data were complete (data for two men were incomplete). They had a mean age of 26.8 (SD 12.8) years, a mean pre-study weight of 68.5 (SD 8.6$) \mathrm{kg}$, and a mean BMI of $22 \cdot 1$ (SD 2.2) $\mathrm{kg} / \mathrm{m}^{2}$.

\section{Body weight and food intake}

Body weight was fairly constant during the study and hardly differed between the two diet periods: the average body weight was 68.7 (SD 8.7) $\mathrm{kg}$ after the oil-rich diet and 68.6 (SD 8.7) kg after the low-fat diet. On average subjects consumed $10.2 \mathrm{MJ} / \mathrm{d}$ of the experimental diets that were provided by us. They consumed an additional $1.1 \mathrm{MJ}$ of free-choice low-fat food items per day. The composition of the total daily food intake (provided food plus free-choice foods) in both periods is given in Table 2 .

\section{Blood lipids}

Serum HDL-cholesterol was $0.21 \mathrm{mmol} / \mathrm{l} \quad(8.1 \mathrm{mg} / \mathrm{dl})$ lower after the low-fat diet than after the oil-rich diet (95\% CI, -0.26, -0.17). Serum total cholesterol was $0.14 \mathrm{mmol} / \mathrm{l}$ lower after the low-fat diet than after the oilrich diet $(95 \% \mathrm{CI}-0 \cdot 27,-0 \cdot 01)$. In contrast, serum triacylglycerols were $0.22 \mathrm{mmol} / \mathrm{l}$ higher after the low-fat diet than after the oil-rich diet (95\% CI 0.12, 0.32). Serum LDL-cholesterol remained stable (Table 3).

The order in which the two diets were taken barely affected the change in HDL-cholesterol: the mean change was -0.23 (SD 0.14) $\mathrm{mmol} / \mathrm{l}$ in subjects who changed from the low-fat to the oil-rich diet and $0 \cdot 20$ (SD $0 \cdot 13$ ) $\mathrm{mmol} / \mathrm{l}$ in subjects who received the diets in the reverse order.

\section{Brachial artery measurements}

The resting and maximum diameter of the brachial artery
Table 3. Concentration of serum lipids (in $\mathrm{mmol} / \mathrm{l}$ ) after consumption of the two diets

(Values are means and their standard deviations for thirty-two subjects)

\begin{tabular}{|c|c|c|c|c|c|}
\hline & \multicolumn{2}{|c|}{ Oil-rich diet } & \multicolumn{2}{|c|}{ Low-fat diet } & \multirow[b]{2}{*}{ Difference $(95 \% \mathrm{Cl})$} \\
\hline & Mean & SD & Mean & SD & \\
\hline Total cholesterol & 4.48 & 0.87 & 4.34 & 0.84 & $-0.14(-0.27,-0.01)$ \\
\hline HDL-cholesterol & 1.66 & 0.39 & 1.44 & 0.35 & $-0.21(-0.26,-0.17)$ \\
\hline LDL-cholesterol & 2.45 & 0.65 & 2.42 & 0.67 & $-0.03(-0.12,0.07)$ \\
\hline Triacylglycerols & 0.81 & 0.41 & 1.03 & 0.52 & $0.22(0.12,0.32)$ \\
\hline
\end{tabular}

were hardly affected by the type of diet (Table 4). FMD was slightly better after the low-fat diet than after the oilrich diet: 4.80 (SD 2.94) \% v. $4.13($ SD 2.72$) \%(P=0.29)$, which was a difference of $-0.67 \%$-units $(95 \% \mathrm{CI},-1.94$, $0 \cdot 61$ ). Subjects who changed from the oil-rich diet to the low-fat diet showed a bigger change in FMD (1.26\%units) than subjects who received the diets in reverse order (0.08\%-units).

All subjects showed vasodilation after nitroglycerin (range 1.1-26.4 \%), indicating that their smooth muscle cells were able to respond to nitric oxide. The type of diet had hardly any effect on nitroglycerin-mediated vasodilation, which was 10.0 (SD 5.1) \% after the low-fat diet and 11.9 (SD 7.3) \% after the oil-rich diet.

\section{Serum homocysteine measurements}

Serum homocysteine concentrations were not affected by the difference in the two diets: concentrations after the lowfat diet were 10.0 (SD 2.5) $\mu \mathrm{mol} / \mathrm{l}$ and after the oil-rich diet $10 \cdot 1$ (SD $2 \cdot 7) \mu \mathrm{mol} / 1$ (difference $0.2 \mu \mathrm{mol} / 1,95 \% \mathrm{CI}-0 \cdot 3$, $0 \cdot 6)$.

\section{Bayesian interpretation}

Before the study we postulated that FMD would be $1 \%$ unit lower after the low-fat diet than after the oil-rich diet. We gave this hypothesis an a priori probability of $75 \%$,

Table 4. Brachial artery measurements after both diets (Values are means and their standard deviations for thirty-two subjects)

\begin{tabular}{|c|c|c|c|c|}
\hline & \multicolumn{2}{|c|}{ Oil-rich diet } & \multicolumn{2}{|c|}{ Low-fat diet } \\
\hline & Mean & SD & Mean & SD \\
\hline Resting diameter (mm) & 3.91 & 0.68 & 3.95 & 0.55 \\
\hline Maximum diameter (mm) & 4.07 & 0.69 & $4 \cdot 13$ & 0.55 \\
\hline Absolute vasodilation (mm) & $0 \cdot 16$ & $0 \cdot 10$ & 0.18 & 0.10 \\
\hline Flow mediated vasodilation (\%)* & $4 \cdot 13$ & $2 \cdot 72$ & 4.80 & $2 \cdot 94$ \\
\hline Endothelium-independent dilation (\%) & 11.9 & $7 \cdot 3$ & $10 \cdot 0$ & $5 \cdot 1$ \\
\hline Systolic blood pressure $(\mathrm{mmHg})$ & 121.9 & $11 \cdot 2$ & $120 \cdot 4$ & 11.5 \\
\hline Diastolic blood pressure (mmHg) & $72 \cdot 2$ & $9 \cdot 1$ & $71 \cdot 0$ & 7.4 \\
\hline
\end{tabular}


Table 5. Change in prior probabilities, ranging from weak to strong, to posterior probabilities using data of the present study

\begin{tabular}{llll}
\hline Prior probability & \multicolumn{1}{c}{ Prior odds } & \multicolumn{1}{c}{ Posterior odds } & Posterior probability \\
\hline 0.75 (strong) & $0.75 /(1-0.75)=3$ & $3 \times$ Bayes factor $^{\star}=0.12$ & $0.12 /(1+0.12)=0.11$ \\
0.50 (equivocal) & $0.50 /(1-0.50)=1$ & $1 \times$ Bayes factor $=0.042$ & $0.042 /(1+0.042)=0.04$ \\
0.25 (weak) & $0.25 /(1-0.25)=0.33$ & $0.33 \times$ Bayes factor $=0.014$ & $0.014 /(1+0.014)=0.014$ \\
\hline
\end{tabular}

A priori probabilities were first converted to a priori odds. The a priori odds were then multiplied by the Bayes factor to obtain a posteriori odds. Finally, the a posteriori odds were converted to a posteriori probabilities.

* Bayes factor $=e$ to the power $Z^{2} / 2$, where $z$ is the $z$-score of the $P$-value for obtaining a result as large as $+0.67 \%$-units under the hypothesis that the result would be $-1.0 \%$-units. $P$-value $=0.0119, z-$ score $=2.52$.

which corresponds with a priori odds of $0 \cdot 75 /(1-0.75)=$ 3. From our data we calculated that the probability $P$ of finding an effect of $-0.67 \%$-units under this hypothesis was $0 \cdot 29$. A $P$-value of 0.29 corresponds with a $z$-score of 2.52 and a minimum Bayes factor of 0.04. This Bayes factor was used to correct the a priori odds into a posterior odds by multiplication. Thus, the a posteriori odds for the hypothesis was $0.04 \times 3=0.12$, which corresponded with an a posteriori probability of the hypothesis of $0 \cdot 12 /(1+$ $0 \cdot 12)=0 \cdot 11$, or $11 \%$ (Table 5). Consequently, smaller a priori probabilities of 50 or $25 \%$ corresponded with even smaller a posteriori probabilities (Table 5).

\section{Discussion}

We found that a change in HDL-cholesterol induced by two different diets, one low in fat and one high in oil, did not change FMD, one of the markers of endothelial function. This suggests that the reduction in HDL-cholesterol by a low-fat, high-carbohydrate diet does not have an adverse effect on vascular functioning in individuals of the type studied here.

\section{Does a reduction in HDL-cholesterol impair endothelial function? From prior to posterior probability}

We expected to find a smaller FMD after the low-fat diet than after the high-oil diet. We based this on data of our previous study and on data of studies of others. In our previous study, a decrease in serum HDL-cholesterol of $0.36 \mathrm{mmol} / \mathrm{l}$ went together with a decrease in FMD of $1.8 \%$-units. We designed the diets in the present study in such a way that a difference in HDL-cholesterol of $0 \cdot 20 \mathrm{mmol} / \mathrm{l}$ could be expected, and thus a difference in FMD of $0.20 / 0.36 \times 1.8 \%$-units or $1 \%$-units. This expectation is based on a positive, linear relation between HDLcholesterol and endothelial function. Indeed, many (Kuhn et al. 1991; Zeiher et al. 1994; Jensen-Urstad \& Rosfors, 1997; O'Brien et al. 1997; Simons et al. 1998; Toikka et al. 1999; Zhang et al. 2000) but not all (Tawakol et al. 1997) cross-sectional studies showed a positive relation between serum HDL-cholesterol and endothelial function. Another reason why we expected to see a decrease in endothelial function after a decrease in HDL-cholesterol is that other studies showed changes in endothelial function when risk factors for CVD were changed. For example, lowering of elevated homocysteine by folic acid improved endothelial function after 6 weeks (Bellamy et al. 1999). Also lowering of LDL-cholesterol by statins (Anderson et al. 1995; Treasure et al. 1995; Vogel et al. 1996a; O’Driscoll et al.
1997; Dupuis et al. 1999) or diet and cholestyramine (Leung et al. 1993) was shown to improve endothelial function. Based on these previous studies, we hypothesised that a predicted decrease in serum HDL-cholesterol of $0.2 \mathrm{mmol} / \mathrm{l}$ would lower FMD by at least $1 \%$-unit. We gave this hypothesis an a priori probability of $75 \%$, but evidently different a priori probabilities may be postulated (Table 5). Based on our data, the hypothesis that a diet low in fat would decrease FMD by the postulated amount became less likely; the a posteriori probability was only $11 \%$. Moreover, a recent study in Australian men and women showed that a low-fat diet decreased serum HDLcholesterol but did not affect arterial elasticity when compared to a diet high in monounsaturated fats (Ashton et al. 2000).

We did not measure HDL composition or particle size. However, it is possible that different diet-induced decreases in HDL-cholesterol have different effects on HDL composition or particle size. Indeed, studies in which fat was replaced by carbohydrates show a change in the composition of HDL particles, with a larger decrease in the antiatherogenic HDL2 subfraction than in the HDL3 subfraction (Berglund et al. 1999; Walden et al. 2000). In contrast, replacement of saturated fat by trans fat decreased serum HDL-cholesterol without changing the composition of the HDL particles (Lichtenstein et al. 1999) and with only a slight decrease in apolipoprotein A-1 (Aro et al. 1997; Müller et al. 1998). However, these differences point at a more atherogenic change in HDL induced by a low-fat diet than by a diet rich in trans fatty acids, and this is not reflected in the changes in FMD.

\section{Other factors in the diets that might have affected endothelial function}

The goal of the two study diets was to achieve a difference in HDL-cholesterol while keeping the diets as equal as possible. Although that goal was reached, there were a number of differences between the diets that might have counteracted an effect of HDL-cholesterol. First, there was a difference in fatty acid composition between the two diets because we wanted to keep serum LDL-cholesterol constant. If we had replaced 20 en\% of carbohydrates with 20 en\% of monounsaturated fatty acids, serum LDLcholesterol would have decreased by $0.12 \mathrm{mmol} / \mathrm{l}$ (Mensink \& Katan, 1992). Thus, the high-oil diet was higher in saturated fat (5 en\%) and polyunsaturated fat ( $2 \mathrm{en} \%)$. The higher intake of saturated fat might have impaired endothelial function, but this is only suggested by shortterm studies that compared high-fat with low-fat meals 
(Vogel et al. 1997b; Ong et al. 1999). On the other hand, the higher intake of polyunsaturated fats might have improved endothelial function because these fats were shown to improve arterial compliance, although at higher intakes (Nestel et al. 1997). The mechanism by which fats might affect endothelial function is not clear, because not all studies show an impairment of endothelial function after a high-fat meal (Williams et al. 1999). It is possible that high concentrations of triacylglycerols in serum cause the impairment because intravenous dosing of triacylglycerols results in impaired endothelial function (Lundman et al. 1997). However, others suggest that, in particular, fats that have been used for deep-frying and are therefore rich in degradation products may impair endothelial function (Williams et al. 1999). Although in our study the concentration of fasting triacylglycerols in serum was higher after the low-fat diet than after the high-oil diet, it is unlikely that this had an effect on endothelial function (Schnell et al. 1999).

The two diets not only differed in fat and carbohydrate content: the intake of fruits and vegetables was also higher on the low-fat diet than on the high-oil diet. We could have kept the intake of fruits and vegetables equal on the two diets, but then the amount of starchy foods, such as potatoes, rich and pasta, would have been too bulky to be appetising. Thus, the intake of some vitamins was different between the diets. We estimate that the daily intake of folate from fruits and vegetables was $25-50 \mu \mathrm{g}$ higher from the low-fat diet than from the high-oil diet (Brouwer et al. 1999). Consequently (Schorah et al. 1998; Brouwer et al. 1999), serum homocysteine concentrations were slightly $(0.2 \mu \mathrm{mol} / \mathrm{l})$ lower after the low-fat diet than after the high-oil diet. This decrease was probably too small to have improved FMD (Bellamy et al. 1999; Wilmink et al. 2000). Another difference between the two diets was vitamin C: the low-fat diet contained about $30 \mathrm{mg} / \mathrm{d}$ more vitamin $\mathrm{C}$ than the high-oil diet. This difference is not likely to have had an effect on endothelial function because studies that had showed an effect of vitamin $\mathrm{C}$ used amounts of 500-1000 mg/d (Plotnick et al. 1997; Duffy et al. 1999; Chambers et al. 1999; Gokce et al. 1999). In contrast to vitamin $\mathrm{C}$ and folic acid, which were higher on the low-fat diet, vitamin $\mathrm{E}$ intake was higher on the high-oil diet, mainly because we used olive oil. However, vitamin $\mathrm{E}$ does not appear to have strong effects on endothelial function (Neunteufl et al. 2000) and the difference between diets was only $10 \mathrm{mg} / \mathrm{d}$, probably too small to have had any effect.

In conclusion, we showed that FMD, one of the markers of endothelial function, was not affected when HDLcholesterol was lowered by substituting carbohydrates for monounsaturated oil. Thus, our data provide no evidence for an adverse effect of low-fat diets on vascular functioning.

\section{Acknowledgements}

We are indebted to the volunteers who took part in the study. We thank Els Siebelink for calculating the diets, Marieke Spaan and Kirsten van den Brink for preparing the diets, Jan Harryvan for the brachial artery measurements,
Rudy Meijer (Radiology Department, University Medical Center Utrecht) for ultrasound training and support and Karin Duiser (Julius Center, University Medical Center Utrecht) for reading the images, Truus Kosmeyer for analysis of the duplicate diets, and Louise and Nadège Beyne, Anke Bongers, Irna Hertel, Marieke de Lange, Judith Manniën, and Karen Oberndorff for their assistance during the study.

This study was financially supported by the Dutch Dairy Foundation on Nutrition and Health.

\section{References}

Anonymous (1996) Nederlands Voedingsstoffenbestand, Den Haag: Voorlichtingsbureau voor de Voeding.

Anderson TJ, Meredith IT, Yeung AC, Frei B, Selwyn AP \& Ganz P (1995) The effect of cholesterol-lowering and antioxidant therapy on endothelium-dependent coronary vasomotion. New England Journal of Medicine 332, 488-493.

Aro A, Jauhiainen M, Partanen R, Salminen I \& Mutanen M (1997) Stearic acid, trans fatty acids, and dairy fat: effects on serum and lipoprotein lipids, apolipoproteins, lipoprotein(a), and lipid transfer proteins in healthy subjects. American Journal of Clinical Nutrition 65, 1419-1426.

Ashton EL, Pomeroy S, Foster JE, Kaye RS, Nestel PJ \& Ball M (2000) Diet high in monounsaturated fat does not have a different effect on arterial elasticity than a low-fat, highcarbohydrate diet. Journal of the American Diet Association 100, 537-542.

Ballantyne CM, Herd JA, Ferlic LL, Dunn JK, Farmer JA, Jones PH, Schein JR \& Gotto AMJ (1999) Influence of low HDL on progression of coronary artery disease and response to fluvastatin therapy. Circulation 99, 736-743.

Bellamy MF, McDowell IF, Ramsey MW, Brownlee M, Newcombe RG \& Lewis MJ (1999) Oral folate enhances endothelial function in hyperhomocysteinaemic subjects. European Journal of Clinical Nutrition 29, 659-662.

Berglund L, Oliver EH, Fontanez N, Holleran S, Matthews K, Ginsberg HN, Ramakrishnan R \& Lefevre M (1999) HDLsubpopulation patterns in response to reductions in dietary total and saturated fat intakes in healthy subjects. American Journal of Clinical Nutrition 70, 992-1000.

Bray GA \& Popkin BM (1998) Dietary fat intake does affect obesity! American Journal of Clinical Nutrition 68, 11571173.

Brouwer IA, van Dusseldorp M, West CE, Meyboom S, Thomas CM, Duran M, van het H, Eskes TK, Hautvast JG \& Steegers-Theunissen RP (1999) Dietary folate from vegetables and citrus fruit decreases plasma homocysteine concentrations in humans in a dietary controlled trial. Journal of Nutrition 129, 1135-1139.

Castelli WP, Anderson K, Wilson PW \& Levy D (1992) Lipids and risk of coronary heart disease. The Framingham Study. Annals of Epidemiology 2, 23-28.

Celermajer DS, Adams MR, Clarkson P, Robinson J, McCredie R, Donald A \& Deanfield JE (1996) Passive smoking and impaired endothelium-dependent arterial dilatation in healthy young adults. New England Journal of Medicine 334, 150-154.

Chambers JC, McGregor A, Jean-Marie J, Obeid OA \& Kooner JS (1999) Demonstration of rapid onset vascular endothelial dysfunction after hyperhomocysteinemia, an effect reversible with vitamin C. Circulation 99, 1156-1160.

Clarke R, Frost C, Collins R, Appleby P \& Peto R (1997) Dietary lipids and blood cholesterol: quantitative meta-analysis of metabolic ward studies. British Medical Journal 314, 112-117. 
Clarkson P, Celermajer DS, Powe AJ, Donald AE, Henry RM \& Deanfield JE (1997) Endothelium-dependent dilatation is impaired in young healthy subjects with a family history of premature coronary disease. Circulation 96, 3378-3383.

Connor WE \& Connor SL (1997) The case for a low-fat, highcarbohydrate diet. New England Journal of Medicine 337, 562563.

de Backer G, de Bacquer D \& Kornitzer M (1998) Epidemiological aspects of high density lipoprotein cholesterol. Atherosclerosis 137, $\mathrm{S} 1-\mathrm{S} 6$.

de Roos NM, Schouten EG \& Katan MB (2001) Consumption of a solid fat rich in lauric acid results in a more favourable serum lipid profile in healthy men and women than consumption of a solid fat rich in trans fatty acids. Journal of Nutrition 131, 242-245.

Duffy SJ, Gokce N, Holbrook M, Huang A, Frei B, Keaney JF Jr. \& Vita JA (1999) Treatment of hypertension with ascorbic acid. Lancet 354, 2048-2049.

Dupuis J, Tardif JC, Cernacek P \& Theroux P (1999) Cholesterol reduction rapidly improves endothelial function after acute coronary syndromes. The RECIFE (reduction of cholesterol in ischemia and function of the endothelium) trial. Circulation 99, 3227-3233.

Gokce N, Keaney JFJ, Frei B, Holbrook M, Olesiak M, Zachariah BJ, Leeuwenburgh C, Heinecke JW \& Vita JA (1999) Long-term ascorbic acid administration reverses endothelial vasomotor dysfunction in patients with coronary artery disease. Circulation 99, 3234-3240.

Goodman SN (1999) Toward evidence-based medical statistics. 2: The Bayes factor. Annals of Internal Medicine 130, 1005-1013.

Gordon DJ, Knoke J, Probstfield JL, Superko R \& Tyroler HA (1986) High-density lipoprotein cholesterol and coronary heart disease in hypercholesterolemic men: the Lipid Research Clinics Coronary Primary Prevention Trial. Circulation 74, 1217-1225.

Gordon DJ, Probstfield JL, Garrison RJ, Neaton JD, Castelli WP, Knoke JD, Jacobs DRJ, Bangdiwala S \& Tyroler HA (1989) High-density lipoprotein cholesterol and cardiovascular disease. Four prospective American studies. Circulation 79, 8-15.

Hulshof KFAM, van Erp-Baart MA \& Anntolainen M (1999) Intake of fatty acids in Western-Europe with emphasis on trans fatty acids: The Transfair Study. European Journal of Clinical Nutrition 53, 143-157.

Huttunen JK, Manninen V, Manttari M, Koskinen P, Romo M, Tenkanen L, Heinonen OP \& Frick MH (1991) The Helsinki Heart Study: central findings and clinical implications. Annals of Medicine 23, 155-159.

Jensen-Urstad K \& Rosfors S (1997) A methodological study of arterial wall function using ultrasound technique. Clinical Physiology 17, 557-567.

Joannides R, Haefeli WE, Linder L, Richard V, Bakkali EH, Thuillez C \& Luscher TF (1995) Nitric oxide is responsible for flow-dependent dilatation of human peripheral conduit arteries in vivo. Circulation 91, 1314-1319.

Katan MB, Grundy SM \& Willett WC (1997) Beyond low-fat diets. New England Journal of Medicine 337, 563-566.

Kitamura A, Iso H, Naito Y, Iida M, Konishi M, Folsom AR, Sato S, Kiyama M, Nakamura M, Sankai T, Shimamoto T \& Komachi Y (1994) High-density lipoprotein cholesterol and premature coronary heart disease in urban Japanese men. Circulation 89, 2533-2539.

Kuhn FE, Mohler ER, Satler LF, Reagan K, Lu DY \& Rackley CE (1991) Effects of high-density lipoprotein on acetylcholineinduced coronary vasoreactivity. American Journal of Cardiology 68, 1425-1430

Leung WH, Lau CP \& Wong CK (1993) Beneficial effect of cholesterol-lowering therapy on coronary endothelium-dependent relaxation in hypercholesterolaemic patients. Lancet $\mathbf{3 4 1}$, $1496-1500$
Lichtenstein AH, Ausman LM, Jalbert SM \& Schaefer EJ (1999) Effects of different forms of dietary hydrogenated fats on serum lipoprotein cholesterol levels. New England Journal of Medicine 340, 1933-1940.

Lundman P, Eriksson M, Schenck-Gustafsson K, Karpe F \& Tornvall P (1997) Transient triglyceridemia decreases vascular reactivity in young, healthy men without risk factors for coronary heart disease. Circulation 96, 3266-3268.

Mensink RP \& Katan MB (1992) Effect of dietary fatty acids on serum lipids and lipoproteins. A meta-analysis of 27 trials. Arteriosclerosis and Thrombosis 12, 911-919.

Miller M, Teter B, Dolinar C \& Georgopoulos A (1998) An NCEP II diet reduces postprandial triacylglycerol in normocholesterolemic adults. Journal of Nutrition 128, 582-586.

Müller H, Jordal O, Kierulf P, Kirkhus B \& Pedersen JI (1998) Replacement of partially hydrogenated soybean oil by palm oil in margarine without unfavorable effects on serum lipoproteins. Lipids 33, 879-887.

Nestel PJ, Pomeroy SE, Sasahara T, Yamashita T, Liang YL, Dart AM, Jennings GL, Abbey M \& Cameron JD (1997) Arterial compliance in obese subjects is improved with dietary plant $n-3$ fatty acid from flaxseed oil despite increased LDL oxidizability. Arteriosclerosis, Thrombosis and Vascular Biology 17, 1163-1170.

Neunteufl T, Heher S, Katzenschlager R, Wslfl G, Maurer G \& Weidinger F (1999) Long-term prognostic value of lowmediated vasodilation in the brachial artery of patients with angina pectoric: results of a 5-year follow-up study. Circulation 100, 1-48 (Abstract).

Neunteufl T, Priglinger U, Heher S, Zehetgruber M, Soregi G, Lehr S, Huber K, Maurer G, Weidinger F \& Kostner K (2000) Effects of vitamin $\mathrm{E}$ on chronic and acute endothelial dysfunction in smokers. Journal of the American College of Cardiology 35, 277-283.

apos;Brien SF, Watts GF, Playford DA, Burke V, O'Neal DN \& Best JD (1997) Low-density lipoprotein size, high-density lipoprotein concentration, and endothelial dysfunction in non-insulin-dependent diabetes. Diabetic Medicine 14, 974978.

O'Driscoll G, Green D \& Taylor RR (1997) Simvastatin, an HMG-coenzyme A reductase inhibitor, improves endothelial function within 1 month. Circulation 95, 1126-1131.

Ong PJ, Dean TS, Hayward CS, Della MP, Sanders TA \& Collins P (1999) Effect of fat and carbohydrate consumption on endothelial function. Lancet 354, 2134.

Pearson TA, Bulkley BH, Achuff SC, Kwiterovich PO \& Gordis L (1979) The association of low levels of HDL cholesterol and arteriographically defined coronary artery disease. American Journal of Epidemiology 109, 285-295.

Plotnick GD, Corretti MC \& Vogel RA (1997) Effect of antioxidant vitamins on the transient impairment of endothelium-dependent brachial artery vasoactivity following a single high-fat meal. JAMA 278, 1682-1686.

Schaefer EJ, Lichtenstein AH, Lamon-Fava S, Contois JH, Li Z, Rasmussen H, McNamara JR \& Ordovas JM (1995) Efficacy of a National Cholesterol Education Program Step 2 diet in normolipidemic and hypercholesterolemic middle-aged and elderly men and women. Arteriosclerosis, Thrombosis, and Vascular Biology 15, 1079-1085.

Schnell GB, Robertson A, Houston D, Malley L \& Anderson TJ (1999) Impaired brachial artery endothelial function is not predicted by elevated triglycerides. Journal of the American College of Cardiology 33, 2038-2043.

Schorah CJ, Devitt H, Lucock M \& Dowell AC (1998) The responsiveness of plasma homocysteine to small increases in dietary folic acid: a primary care study. European Journal of Clinical Nutrition 52, 407-411. 
Sharrett AR, Sorlie PD, Chambless LE, Folsom AR, Hutchinson RG, Heiss G \& Szklo M (1999) Relative importance of various risk factors for asymptomatic carotid atherosclerosis versus coronary heart disease incidence. American Journal of Epidemiology 149, 843-852.

Simons LA, Sullivan D, Simons J \& Celermajer DS (1998) Effects of atorvastatin monotherapy and simvastatin plus cholestyramine on arterial endothelial function in patients with severe primary hypercholesterolaemia. Atherosclerosis 137, 197-203.

Sorensen KE, Celermajer DS, Spiegelhalter DJ, Georgakopoulos D, Robinson J, Thomas O \& Deanfield JE (1995) Non-invasive measurement of human endothelium dependent arterial responses: accuracy and reproducibility. British Heart Journal 74, 247-253.

Sorlie PD, Sharrett AR, Patsch W, Schreiner PJ, Davis CE, Heiss G \& Hutchinson R (1999) The relationship between lipids/lipoproteins and atherosclerosis in African Americans and whites: the Atherosclerosis Risk in Communities Study. Annals of Epidemiology 9, 149-158.

Tawakol A, Omland T, Gerhard M, Wu JT \& Creager MA (1997) Hyperhomocyst(e)inemia is associated with impaired endothelium-dependent vasodilation in humans. Circulation 95, 11191121.

Toikka JO, Ahotupa M, Viikari JS, Niinikoski H, Taskinen M, Irjala K, Hartiala JJ \& Raitakari OT (1999) Constantly low HDL-cholesterol concentration relates to endothelial dysfunction and increased in vivo LDL-oxidation in healthy young men. Atherosclerosis 147, 133-138.

Treasure CB, Klein JL, Weintraub WS, Talley JD, Stillabower ME, Kosinski AS, Zhang J, Boccuzzi SJ, Cedarholm JC \& Alexander RW (1995) Beneficial effects of cholesterol-lowering therapy on the coronary endothelium in patients with coronary artery disease. New England Journal of Medicine 332, 481-487.

Turley ML, Skeaff CM, Mann JI \& Cox B (1998) The effect of a low-fat, high-carbohydrate diet on serum high density lipoprotein cholesterol and triglyceride. European Journal of Clinical Nutrition 52, 728-732.
Ubbink JB, Hayward Vermaak WJ \& Bissbort S (1991) Rapid high-performance liquid chromatography assay for total homocysteine levels in human serum. Journal of Chromatography $\mathbf{5 6 5}, 441-446$.

Ueland PM, Refsum H, Stabler SP, Malinow R, Andersson A \& Allen RH (1993) Total homocysteine in plasma or serum: methods and clinical applications. Clinical Chemistry 39, 1764-1779.

Vogel RA, Corretti MC \& Plotnick GD (1996a) Changes in flowmediated brachial artery vasoactivity with lowering of desirable cholesterol levels in healthy middle-aged men. American Journal of Cardiology 77, 37-40.

Vogel RA, Corretti MC \& Plotnick GD (1997b) Effect of a single high-fat meal on endothelial function in healthy subjects. American Journal of Cardiology 79, 350-354.

Walden CE, Retzlaff BM, Buck BL, Wallick S, McCann BS \& Knopp RH (2000) Differential effect of National Cholesterol Education Program (NCEP) Step II diet on HDL cholesterol, its subfractions, and apoprotein A-I levels in hypercholesterolemic women and men after 1 year: the beFIT Study. Arteriosclerosis, Thrombosis and Vascular Biology 20, 1580-1587.

Williams MJA, Sutherland WHF, McCormick MP, de Jong SA, Walker RJ \& Wilkins GT (1999) Impaired endothelial function following a meal rich in used cooking fat. Journal of the American College of Cardiology 33, 1050-1055.

Wilmink HW, Stroes ES, Erkelens WD, Gerritsen WB, Wever R, Banga JD \& Rabelink TJ (2000) Influence of folic acid on postprandial endothelial dysfunction. Arteriosclerosis, Thrombosis Vascular Biology 20, 185-188.

Zeiher AM, Schachlinger V, Hohnloser SH, Saurbier B \& Just H (1994) Coronary atherosclerotic wall thickening and vascular reactivity in humans. Elevated high-density lipoprotein levels ameliorate abnormal vasoconstriction in early atherosclerosis. Circulation 89, 2525-2532.

Zhang X, Zhao SP, Li XP, Gao M \& Zhou QC (2000) Endothelium-dependent and -independent functions are impaired in patients with coronary heart disease. Atherosclerosis 149, 19-24. 